\title{
Perception of family caregivers about barriers of leisure in care of individuals with chronic psychiatric disorders: a qualitative study
}

Batool Mandani ${ }^{1}$, Seyed Ali Hosseini ${ }^{2}$, Mohammad Ali Hosseini ${ }^{3}$, Ashraf Karbalaie Noori ${ }^{4}$, Mohammad Reza Khodaie Ardakani ${ }^{5}$

${ }^{1}$ Ph.D. Candidate of Occupational Therapy, Department of Occupational Therapy, University of Social Welfare and Rehabilitation Sciences, Tehran, Iran

${ }^{2}$ Ph.D., Professor, Department of Occupational Therapy, Social Determinants of Health Research Center, University of Social Welfare and Rehabilitation Sciences, Tehran, Iran

3 Ph.D., Associate Professor, Department of Rehabilitation Management, University of Social Welfare and Rehabilitation Sciences, Tehran, Iran

${ }^{4}$ Ph.D., Assistant Professor, Department of Occupational Therapy, University of Social Welfare and Rehabilitation Sciences, Tehran, Iran

${ }^{5}$ MD., Psychiatrist, Professor, Social Determinants of Health Research Center, University of Social Welfare and Rehabilitation Sciences, Tehran, Iran

Type of article: Original

\begin{abstract}
Background: Family caregivers of individuals with chronic psychiatric disorders play an important role in the management of the patient's conditions, which interferes with other activities of daily living, work, social and leisure activities.

Objective: This study was conducted in an Iranian context to explore the perception of family caregivers about barriers of leisure in care of individuals with chronic psychiatric disorders.

Methods: The current qualitative study was conducted on the basis of conventional content analysis. Participants were 15 family caregivers of individuals with chronic psychiatric disorders who were selected by Purposeful sampling method between July 2016 and March 2017 in Tehran, Iran. The data was collected via in-depth semistructured interviews. The interviews were tape recorded, written and transcribed. Then, data were analyzed by inductive content analysis method.

Results: Data analysis led to extraction of 3 main categories and 10 sub categories. Obstacles to leisure-time of family caregivers have been placed in three main categories which are patient-related factors (Resentment from psychological problems, Resentment from behavioral problems, Need for continuous monitoring and access), caregiver-related factors (Physical harm, Psychosocial harm, Temporal stress, Accumulation of responsibilities, Concerns), and community-related factors (Feeling of sympathy and rejection, Social stigma).

Conclusion: Understanding the barriers of leisure in this group of family caregivers has contributed to understanding the family caregivers' perception in this area and regarding their leisure, it can provide a broader perspective to mental health therapists, rehabilitation managers and policy makers for understanding the needs, addressing the challenges and barriers of this group of family caregivers.

Keywords: Leisure, Family caregivers, Chronic psychiatric disorders, Qualitative study, Barrier
\end{abstract}

\section{Corresponding author:}

Professor Dr. Seyed Ali Hosseini, Department of Occupational Therapy, Social Determinants of Health Research Center, University of Social Welfare and Rehabilitation Sciences, Tehran, Iran.

Tel: +98.2122180037, Email: alihosse@gmail.com

Received: August 09, 2017, Accepted: September 20, 2017, Published: March 2018

iThenticate screening: September 03, 2017, English editing: February 12, 2018, Quality control: February 15, 2018

This article has been reviewed / commented by five experts

(C) 2018 The Authors. This is an open access article under the terms of the Creative Commons Attribution-NonCommercialNoDerivs License, which permits use and distribution in any medium, provided the original work is properly cited, the use is non-commercial and no modifications or adaptations are made. 


\section{Introduction}

Mental illness is one of the main forms of chronic disease that results in functional disability, difficulty in performance and roles (1). The occurrence of psychiatric disorders in a family can be a stressful event or a crisis among its members; it can change their living conditions and can impact their mental health $(2,3)$. Caregiving and the presence of caregivers for individuals with chronic psychiatric disorders are both common and necessary. Family caregivers become de facto care providers and they play an important role in the management of conditions of the patients and provide a significant amount of support and services for them (4). Family caregivers, family members, relatives and family friends, who are close to the individual with a physical and mental disability, provide services without receiving any money or expenses (5). Ordinary routines of family caregivers include caring for individuals with chronic illness, medication management, communicating with a doctor or nurses in relation to the patient, helping to wash, bathe and dress the patient, and caring for and monitoring eating or giving medications to the patient $(6,7)$. Studies have shown that family caregivers or family members of psychiatric patients who resided with their sick relative spend at least 35 hours a week in caregiving activities, which can intervene in their daily self-care, work, and social and leisure activities (8). Caregivers may experience further physical and psychological stresses which ultimately affect their performance, all aspects of their life, and quality of life, thus it affects the quality of care provided by them $(6,9)$. In a study by De Silva and De Silva, it was stated that $54 \%$ of caregivers faced difficulties in their everyday life (10). Among all the daily activities of life, leisure activities can be a way to create happier moments and be more beneficial to caregivers and individuals with disabilities (11). Leisure is a nonobligatory activity that an individual is intrinsically motivated and engaged in during discretionary time, that is, time not committed to obligatory occupations such as work, self-care, or sleep (12). Studies have shown that leisure pursuits are important to caregivers' psychological and physical health and wellbeing, and have a positive effect on self-esteem, an increase in life satisfaction, and a decrease in loneliness, while limitation in leisure pursuits leads to an increase in physical and emotional stress (13-15). Reduction or abandonment of leisure time is one of the most important negative consequences of caregiving (16). The National Family Caregivers Association stated that family caregivers in the United States identified loss of leisure as one of the top three important negative outcomes of caregiving $(15,17,18)$. More than half of the family caregivers with chronic diseases have reported limitation in their leisure time, such as travel, holidays and hobbies (19). Non-participation in satisfactory activities by the caregiver can lead to social withdrawal and isolation, depression and risk of emotional disturbances (20). Therefore, taking care of a person with chronic mental illness can be an obstacle for leisure activities of the caregiver and family caregivers (18). Despite the importance of leisure in family caregivers of psychiatric patients and based on the search made in data sources, unfortunately limited evidence was found regarding the barriers of leisure in this group of caregivers in Iran and there is a dearth of understanding among practitioners with respect to this phenomenon. Supportive and educational programs need to recognize all aspects of the family caregivers' perceptions about their leisure clearly. Since people's perception of leisure barriers is a completely mental and sociocultural phenomenon, a qualitative approach is more capable for an in depth study of a mental phenomenon and one with sociocultural aspect (21). This study, with a qualitative approach was conducted in an Iranian context, to explore the perception of family caregivers about barriers of leisure in care of individuals with chronic psychiatric disorders.

\section{Material and Methods}

\subsection{Design}

This qualitative study was conducted by using conventional content analysis (22). The purpose of this study was to explore the barriers to leisure in Iranian family caregivers of individuals with chronic psychiatric disorders. Constant comparative analysis was deployed for data analysis. According to participants' experiences and perceptions, obvious and hidden concepts were identified, concepts and codes were summarized, and categorized based on differences or similarities, and main categories were developed.

\subsection{Participants}

Fifteen family caregivers who lived with a family member or a close relative having a psychiatric disorder in Tehran (Iran) took part in this study. The demographic characteristics of participants are presented in Table 1. Sample selection was done with Purposeful sampling method while taking into account the maximum variation based on the type of disorder, the severity of the disease, duration of psychiatric disorder, age, gender, socioeconomic status and duration of involvement of family caregivers in providing services and care. Family caregivers who were recruited for the purpose of this study were more than 18 years old and had willingness to participate in this study and describe their experience. Exclusion criteria were the caregiver having psychiatric disorders diagnosed by a psychiatrist, serious functional problems, lack of reading and writing skills, and inability to communicate verbally. 
Participants would also be excluded from the study if they did not attend the interview or discontinued the interview. None of the participants left the study or were excluded. The study settings were a psychiatric hospital (Razi Psychiatric Hospital), a private center (Saman Psychiatric Rehabilitation Center) and daily centers (Nezam Mafi Rehabilitation Center, Akhavan Rehabilitation Center). Sampling continued until data saturation.

\subsection{Data collection}

The data were collected via in-depth, semi-structured face to face interviews. The semi-structured interview is an upright tool for exploring the participants' experiences and providing a good atmosphere for them to express their views and attitudes. After obtaining permission from the university's ethics committee to collect information, interviews were carried out by the first author (BM, a PhD candidate of occupational therapy, with 14 years clinical experience) between July 2016 and March 2017 in psychiatric hospital, psychiatric daily centers and clinics. Only the interviewer and participant were present at the interview. The author began the interview after introducing herself and her specialty and expressing the objectives of the interview. Each interview began with an open-ended question (e.g. Would you like to express your experience and perception about your leisure activities?" or "What are the obstacles on your way to engaging in leisure activities?"). Interviews also contained probing questions (e.g. "Can you give me an example of what problems you had when you were having fun?" and" Please speak more about it?"). The follow-up questions were asked according to information provided by the participant to clarify the concept under study. Questions in later interviews were arranged according to categories extracted. Data collection was continued until saturation. Data were considered saturated when no more codes could be identified and properties and dimensions of the category were coherent or made sense. In this research, saturation findings were obtained after 13 interviews and the 2 last interviews were conducted to ensure saturation. The duration of the interviews was between 60 and 90 minutes depending on the tolerance and interest of the caregivers in explaining their own experiences.

\subsection{Data analysis}

Data analysis used, was conventional content analysis by constant comparison method. Interviews were taperecorded and transcribed verbatim. Information obtained was repeatedly read to gain a general understanding of it. Then, interviews were analyzed by inductive qualitative content analysis, which deals with interpretation and can vary in depth and level of abstraction (23). For data analysis, the MAXQAD10 software (Germany, 2007) was utilized. The data were divided into meaning units, labeled as codes, compared constantly to develop sub-categories and categories. Condensing meaning units was done by a process of reducing the text, while maintaining its core, and was coded accordingly. After the process of coding and grouping the codes and obtaining underlying meanings, they were interpreted as main categories (23).

\subsection{Trustworthiness}

The researchers aimed to improve the validity of data through long-term involvement, integration of data, review and professional member check, and constant comparison of data (24). We used strategies recommended by Lincoln and Guba (1981) for trustworthiness of our data. According to this recommendation, 4 criteria of creditability, dependency, conformability, and transferability are necessary for trustworthiness (25). Data credibility was carried out by placing the researcher through ongoing engagement between the data and constant comparison of data, as well as the availability of various experts, including the psychiatrist, psychologist and occupational therapist to increase the credibility of the data. The reliability of the study was achieved using the views of participants and some colleagues on the accuracy of the data analysis. The study approval was attained by submitting reports to 8 professors and confirming them. Sampling was done in consideration of maximum variation. Offering a comprehensive description of the subject, participants, data gathering and data analysis could provide transferability of the study, so that other researchers could continue the study.

\subsection{Ethical considerations}

In this study, as part of the ethical considerations, the following was observed: confidentiality of information; written informed consent to conduct and record interviews; observation, and the right to withdraw at any time during the study. This study was adapted from the first author's PhD thesis, and was approved by the Ethics Committee of the University of Social Welfare and Rehabilitation Sciences (ethic code IR.USWR.REC.1394.385).

\section{Results}

The participants in the study included 15 people (5 men and 10 women), in which the family caregivers had different relationships with the respective patients. Some of the demographic characteristics of the participants are 
shown in Table 1. Categories were derived from the data that reflected the barriers to leisure in family caregivers of individuals with chronic psychiatric disorders. Data analysis led to the extraction of the 3 main categories (patientrelated factors, caregiver related factors and community related factors) and 10 sub- categories (Table 2).

Table 1. Demographic characteristics of participants

\begin{tabular}{|c|c|c|c|c|c|c|c|c|}
\hline $\begin{array}{l}\text { Participant } \\
\text { no. }\end{array}$ & Gender & Education & Occupation & $\begin{array}{l}\text { Caregiver } \\
\text { age (year) }\end{array}$ & $\begin{array}{l}\text { Patient's } \\
\text { age (year) }\end{array}$ & $\begin{array}{l}\text { Duration of } \\
\text { caregiving } \\
\text { (year) }\end{array}$ & $\begin{array}{l}\text { Relation } \\
\text { with the } \\
\text { disabled }\end{array}$ & Diagnosis \\
\hline 1 & Female & $\begin{array}{l}\text { High School } \\
\text { diploma }\end{array}$ & Housewife & 50 & 30 & 16 & Mother & Schizophrenia \\
\hline 2 & Female & $\begin{array}{l}\text { Not completed } \\
\text { High School }\end{array}$ & Retired & 54 & 29 & 15 & Mother & Bipolar disorder \\
\hline 3 & Male & $\begin{array}{l}\text { Not completed } \\
\text { High School }\end{array}$ & $\begin{array}{l}\text { Oil company } \\
\text { employee }\end{array}$ & 70 & 47 & 27 & Father & Schizophrenia \\
\hline 4 & Female & $\begin{array}{l}\text { Not completed } \\
\text { High School }\end{array}$ & Housewife & 61 & 47 & 27 & Mother & Schizophrenia \\
\hline 5 & Female & $\begin{array}{l}\text { Not completed } \\
\text { High School }\end{array}$ & Retired & 56 & 25 & 12 & Mother & Schizoaffective \\
\hline 6 & Female & $\begin{array}{l}\text { Elementary } \\
\text { school }\end{array}$ & Housewife & 46 & 53 & 19 & Wife & $\begin{array}{l}\text { Schizoaffective \& } \\
\text { addiction }\end{array}$ \\
\hline 7 & Female & $\begin{array}{l}\text { High School } \\
\text { diploma }\end{array}$ & Housewife & 56 & 61 & 42 & Sister & Schizophrenia \\
\hline 8 & Male & $\begin{array}{l}\text { High School } \\
\text { diploma }\end{array}$ & Turner & 60 & 32 & 18 & Uncle & $\begin{array}{l}\text { Anxiety disorder \& } \\
\text { depression }\end{array}$ \\
\hline 9 & Female & Under graduate & Retired & 73 & 67 & 45 & Sister & Personality disorder \\
\hline 10 & Male & $\begin{array}{l}\text { Elementary } \\
\text { school }\end{array}$ & $\begin{array}{l}\text { Municipal } \\
\text { worker }\end{array}$ & 42 & 25 & 6 & $\begin{array}{l}\text { Sister's } \\
\text { husband }\end{array}$ & Bipolar disorder \\
\hline 11 & Male & $\begin{array}{l}\text { High School } \\
\text { diploma }\end{array}$ & Carpenter & 59 & 64 & 35 & Brother & $\begin{array}{l}\text { Paranoid } \\
\text { schizophrenia }\end{array}$ \\
\hline 12 & Female & $\begin{array}{l}\text { High School } \\
\text { diploma }\end{array}$ & Housewife & 48 & 23 & 9 & Mother & Schizophrenia \\
\hline 13 & Male & $\begin{array}{l}\text { High School } \\
\text { diploma }\end{array}$ & Businessman & 59 & 26 & 15 & Father & Bipolar disorder \\
\hline 14 & Female & $\begin{array}{l}\text { Not completed } \\
\text { High School }\end{array}$ & Retired & 64 & 33 & 20 & Mother & $\begin{array}{l}\text { Anxiety disorder \& } \\
\text { depression }\end{array}$ \\
\hline 15 & Female & $\begin{array}{l}\text { High School } \\
\text { diploma }\end{array}$ & Housewife & 48 & 27 & 11 & Mother & Personality disorder \\
\hline
\end{tabular}

Table 2. Main categories and subcategories

\begin{tabular}{|l|l|}
\hline Categories & Subcategories \\
\hline Patient related factor & Resentment from psychological Problems \\
\cline { 2 - 2 } & Resentment from behavioral Problems \\
\cline { 2 - 2 } & Resentment from Behavioral Problems \\
\hline Caregiver related factor & Physical harm \\
\cline { 2 - 2 } & Psychosocial harm \\
\cline { 2 - 2 } & Temporal stress \\
\cline { 2 - 2 } & Accumulation of responsibilities \\
\cline { 2 - 2 } & Concerns \\
\hline Community related factor & Feeling of sympathy and rejection \\
\cline { 2 - 2 } & Social stigma \\
\hline
\end{tabular}

\subsection{Patient-related factors}

Participants said that the needs of the patient, the problems that the patients create and the complications of these problems have led to the reduction or abandonment of their leisure activities. This category has 3 sub- categories which are "Resentment from psychological Problems", "Resentment from Behavioral Problems" and "Need for Continuous Monitoring and Access": 


\subsubsection{Resentment from psychological Problems:}

Participants stated that the patient's psychological symptoms and problems including delusions, hallucinations, lack of interest, apathy, and flat affect etc. are among the factors preventing them from engaging in recreational and leisure activities. These symptoms are very frustrating to family caregivers and disrupt their overall lifestyle and prevent them from engaging in leisure activities. One of the participants regarding this matter stated: “...When his symptoms and condition were bad and when his psychiatric symptoms like hallucination and delusion recurred, our whole life was affected by the patient. That is all, we had to take care of him all of our time, at times his actions were out of his own hands, he punched the wall, and he spoke to himself. We always had to be by his side, pay attention to him, not for a moment could we get away from it. We could not afford to go for a break or take advantage of our free time..." (Participant No. 1, 50 years old, woman) Another participant regarding the lack of interest, apathy, lack of motivation, and low tolerance of the patient who prevented their leisure and recreational activities stated: “...On day trips she naturally causes problems, she quickly becomes tired, when we go somewhere she grumbles too much, for example when we go somewhere and half an hour walk is needed, like a mountain walk, she says she is bored and does not like to go anywhere with us. She does not go with us and she causes limitation for us. Because of this we prefer not to go anywhere, it's the same case when going on visits..." (Participant No. 13, 59 years old, man).

\subsubsection{Resentment from Behavioral Problems:}

Participants reported that abnormal, unpredictable and aggressive behaviors and violent actions by the patient prevented them from engaging in leisure activities. In this regard, one of the caregivers says: “...Two times we traveled with our patient, but we encountered a lot of problems and the rest of my children got so bothered. For example, when traveling to the north of the country, the Ministry of Education gave us accommodation. There, he argued with his brother and sister. He fought with them and beat them, he also fought with other people, and he broke the door of the villa that was given to us. So I saw that it is better if I don't go anywhere..." (Participant No. 5,56 years old, woman).

\subsubsection{Need for Continuous Monitoring and Access:}

The need for patient monitoring and continuous access in all matters, permanent presence of the patient next to them, being available at all time and being on-call day and night, makes taking care of oneself become neglected. It was mentioned as one of the obstacles that caregivers addressed as an issue regarding leisure. One of the participants says: "...As I wake up in the morning, I often have to tell him to take bath and brush his teeth. I argue so much with him that I completely forget about myself. I constantly have to remind him of all his chores and I must always pay attention to him. I do not pay much attention to myself or have any fun. I cannot do the things I like at all..." (Participant No. 12, 48 years old, woman). Another point that family caregivers point out is the permanent presence of the patient at home, which requires constant monitoring and access from a watchful caregiver while neglecting their own affairs. One of the family caregivers said: "... I am always paying attention to my ill son and what he does, ensuring that he does not make a mess or harm others and himself, I always have to be beside him or to be on call, because of this, I am not much to myself..." (Participant No. 1, 50 years old, woman).

\subsection{Caregiver related factors}

Participants said that their physical and psychosocial problems, not having enough time, long-term and heavy responsibility for a dependent patient, their permanent adaptation to the specific circumstances, their concerns and the permanent presence of the patient's problem on their minds have led to the reduction or abandonment of their leisure activities. This category has 5 sub-categories which are "physical harm", "psychosocial harm", "temporal stress", "accumulation of responsibilities" and "concerns".

\subsubsection{Physical harm:}

Participants considered a lot of physical energy was needed to address all their affairs and those of the patients, as well as the presence of physical and neurologic pain, while pain is one of the obstacles to leisure activities. One of the participants stated: “...I suffer from heart problems and heart ache due to nervous pressure and stress after my brother became mentally sick. I used to climb in my leisure time, but because of my heart problems, I quit climbing..." (Participant No. 11, 59-year-old, man). Other caregiver says "...Because of the pressures, I am a nervous wreck, but I try to take care of myself and my patient. It takes too much physical energy to manage the chores, so no more energy is left to do recreational and leisure activities..." (Participant No. 2, 54 years old, woman).

\subsubsection{Psychosocial harm:}

Psychosocial harm which causes anxiety, depression, lack of interest and motivation, feeling frustrated and so on, are among caregiver related factors that prevented leisure activities. A participant said: “...If I say that I don't do much for myself except for praying or having a little rest, I haven't lied. From morning until 12 at night I just walk 
and attend to my sick husband and others. I do not spend much time on myself and don't like to go somewhere or doing any leisure activities. When I was single, I wasn't like this but after marrying my mentally ill husband, I do not have the incentive or any motivation to do my own chores or take care of myself. I always like to be by myself and be alone, I feel depressed..." (Participant No. 6, 46 years old, woman). Another participant expressed her lack of motivation and low self-esteem with the following: "...You have no motivation to entertain yourself and to do the work you want to do. All I could think of was our patient. In short, you just don't think of yourself, that's all. I felt bad about myself all the time. I had low self-esteem and I think I was not a good mother, a good wife, a good employee or a good sister. I felt like I was divided in many places, and I was not useful anywhere, so how could I really think of myself..." (Participant No. 9, 73 years old, woman).

3.2.3. Temporal stress:

Lack of time, introduced by all the participants, was considered as one of the main barriers to caring leisure activities. They acknowledged that since they devote a lot of time in taking care of the patient, they no longer have time to spend on their leisure. One of the participant in this case said: “...There are a lot of things I like to do, but I do not have the time. I really like to study foreign language but I never have the time, taking care of the patient's health is too much and it engages me in ways that I can't keep up with house chores let alone doing leisure activities and taking care of myself..." (Participant No. 12, 48 years old, woman). Another participant stated: “...The patient's chores are too much and take much of my time, which leaves me with no time to spend on myself. I may have only one hour in a day to myself which, in that time, I engage in reading. There are many things I like to do but I don't have the time for them..." (Participant No.5, 56 years old, woman).

\subsubsection{Accumulation of responsibilities:}

Participants stated that long-term care of a patient that affects others in most functional areas, imposes a heavy burden on them. It was also argued that the existence of many occupations and responsibilities in addition to the responsibility for caring of the patient such as work, maintenance and care of other family members, home care, care for elderly in the family and other responsibilities are some of the issues that prevent them from engaging in leisure activities. One of the participants said: “...When we used to keep the patient at home and he was not admitted, I had to do all the house chores. I cooked, cleaned the house, fed the kids, I checked their learning progress in school as much as I could. I had to take care of them and also take care of the patient, and taking care of him was a heavy responsibility, I had to do all of his personal stuff, he can't do anything by himself and he is totally dependent on me. I even used to forget that I have to take care of myself too let alone having fun and going out..." (Participant No. 4, 61 years old, woman).

3.2.5. Concerns:

Another barrier to spending time for leisure is family caregivers' constant concern about the course of the illness, course of the treatment, side effects of the medication, the future of the illness and the patient's future. They stated that these concerns and the constant engagement of thought with patient issues did not make it possible for them to think and pursue a topic other than patient issues. One of the participants stated: “...Our mind is always involved around our patient. Most of the things that our minds are involved with are that he does not hurt himself and does not hurt others. We always think what the future of the illness will be, what his future will be, and what will happen to him if we are not around. These thoughts and concerns bother me. I am always concerned about him to such a length that I can't think of myself and my interests. I left school and a job which I was interested in, I didn't have the right mood or the concentration in my studies and university. After my high school diploma, I used to go to English language classes but I couldn't concentrate because my mind was busy with my sick brother..." (Participant No. 7, 56 years old, woman).

\subsection{Community-related factors}

Through interviews, participants addressing their leisure activities, considered feelings of sympathy and being pitied, exclusion and becoming distanced from their associates and acquaintances as well as social stigma as barriers in the community. This category also had 2 subcategories of "feelings of sympathy and rejection" and "social stigma".

3.3.1. Feeling of sympathy and rejection:

Participants felt the sympathy and pity of their relatives and acquaintances as being the obstacles to leisure activities. One of the family caregivers in this regard stated: “...Because of my ill son, I didn't like and didn't want to go out and make relationships or visit anyone. Have you seen when you tell people that your son is mentally ill? They look at you with pity and I don't like to see pity and sympathy from others. This is too hard on us and annoying to us, and keeps us from vesting in others and being in groups..." (Participant No. 2, 54 years old, woman). Participants also said that rejection of the patient by relatives was one of the reasons for avoiding contact with friends and relatives. One of the family caregivers stated: “...When we go out or go to visit someone, or we are with the family, he talks 
too much and because he can't keep up with manners and customs, he is annoying to others. For example, when he wants something, he insists too much, others can't tolerate this attitude of him and reject him. Because of this, most of the time we prefer not to visit friends and family..." (Participant No. 8, 60 years old, man).

\subsubsection{Social stigma:}

Participants proposed social stigma as one of the obstacles to engaging in leisure. They stated that the stigma of mental illness is an obstacle to social relationship and prevents participation in recreational and travel companionships. One of the participants said: “...After the onset of his illness, we didn't visit family members we didn't want them to know that my brother was mentally ill and we didn't want them to find out that he was at a mental institute, we didn't want him to have the label of being mad or mentally ill. We cut off all of our relationships. Taking him to the park would give us the feeling that everyone was watching him and looking at him awkwardly. Some people laughed, some kept their distance and some were afraid of him. Because of these attitudes, we abandoned leisure activities and even traveling..." (Participant No. 9, 73 years old, woman).

\section{Discussion}

As mentioned above, one of the negative consequences of caregiving is not spending time on leisure activities and missing leisure and recreation $(13,18,26)$. The results of this study showed that family caregivers of individuals with chronic psychiatric disorders are forced to reduce, or leave their leisure activities so that they can spend more time and energy on the patient, and there are barriers to engaging in leisure activities by these people. The findings of the study show that these barriers include patient-related factors, caregiver-related factors and community-related factors. One of the patient-related factors was resentment from psychological problems, and according to family caregivers, these symptoms impose a lot of pressure on them. A 2014 study by Jagannathan et al. showed that the amount of stress and burden that caregivers of patients with schizophrenia experience depends on the patient's psychopathology and level of psychological and behavioral problems (27). The more severe the symptoms are, the more pressure on the caregivers there will be (28). According to family caregivers, this pressure can disrupt lifestyle and be an obstacle in the path of their leisure activities. Psychiatric symptoms that the patient shows and manifests can lead to isolation and exclusion of the family, reduce the reputation, and also can reduce their interaction with the community, neighbors, friends and relatives (29). According to the findings of this study, not only do the patient's psychological problems prevent the leisure activities of the caregiver, but his behavioral problems including abnormal, unpredictable and aggressive behaviors, are an obstacle in the path of the caregivers' leisure activities, which has consistency with the results of a 2004 study by Gladwell and Bedini (16). In their study, they stated that among the obstacles to the caregiver's involvement in leisure activities are the worries and the fears of the patient's behavioral problems. They fear so much of abnormal and unpredictable behaviors from the patient and do not know how to react in the face of these behaviors (16). Family caregivers did not know how to control or manage the patient's maladaptive behaviors and they lived under constant strain, therefore contact with mental health therapists is unavoidable.

Other factors related to the patient were the need for continuous monitoring and access. The constant presence of the patient at home and his need for full supervision and continuous access is a barrier to family caregivers in dealing with their leisure activities. A 2010 study by Johansson et al. showed that mothers should always monitor their dependent child, be alert, vigilant and always be available because of the constant presence of their sick child, and this puts a constant emotional and physical strain and stress on the caregiver (30). Because of the patient's need for constant supervision, the caregiver is required to always be available, they described a sense of "hanging on" and their holidays and normal family processes were affected (4). Concern of family caregivers in this regard is the lack of day care centers and outpatient centers throughout the country, and the majority of caregivers had no support from the health care system. Increasing these facilities, equipment and daily services and spending part of the patient's time in these centers can be effective in reducing this burden and responsibility. Based on the findings of the present study, physical harm, psychosocial harm, temporal stress, accumulation of responsibilities and concerns were caregiver related factors that according to participants, considered as barriers to caregivers leisure activities. Participants in the study stated that taking care of the patient was followed by experience in some problems, pains and physical dysfunction. This issue has also been addressed in previous research in this area $(13,15,27,31,32)$. A 2000 study by Chou et al. argued that caregivers reported general physical complaints such as fatigue and chronic muscle aches, insomnia or lack of sleep, heart problems, digestive problems, and weight changes due to the high pressures from care responsibilities (31). These physical illnesses could interfere with and prevent one's participation in leisure activities such as social interactions, hobbies, sports and fitness activities (14). Participants in the study believed that these physical problems were some of the obstacles to the pursuit of their leisure activities. The psychosocial harm was another issue raised by the participants in this research. They said that following the 
patient care process, they also experienced problems in mental health, emotional dysfunction and mood changes, including depression, anxiety, mental fatigue, lack of interest and motivation and these are obstacles in the pursuit of their leisure activities. Previous studies also suggested that caregivers of patients with psychiatric disorders experience problems such as depression, anxiety, pressure, and fatigue (13-15,33). Considering the importance of caregivers' problems, psychoeducational programs such as stress management and life skills training are recommended for them. Joining a support group could be one way of easing these problems.

Temporal stress and lack of time were other important barriers to participants' involvement in leisure. Given that family caregivers spend a lot of time taking care of the patient, they no longer have time to engage in their leisure activities. This finding was in line with the findings of some previous studies. The Family Caregivers Alliance (1995) stated that $51 \%$ of family caregivers reduced the amount of time spent on leisure after becoming caregivers and starting the patient care process, and they had to reduce and change their participation in hobbies, religious activities, recreational activities and sport (34). Reduction in the time available due to increased work and responsibilities is a barrier in pursuing leisure activities such as getting in touch with friends and recreation for caregivers $(14,26,35)$. Education of time management strategies and providing the opportunity to share responsibility with someone else can be survival strategies to have time for one's own activities. Accumulation of responsibilities was one of the other caregiver related factors that prevented participants from engaging in leisure activities. Excessive occupation and responsibilities, in addition to the long-term responsibility of caring for the patient and permanent adaptation to new and emerging circumstances, make family caregivers excessively fatigued and lacking sufficient energy to take care of their affairs, especially their leisure activities (30). The findings of this study are in line with the findings of some previous studies. A 2004 study by Bedini and Phoenix stated that despite caregivers' intrinsic desire for having recreational activities, they find it hard to keep leisure in their lives when they take on the caring responsibilities of a loved one (15). A 1996 study by Bedini and Guinan showed that caregivers, especially women, are often forced to abandon social interactions, hobbies, religious activities, and physical and sporting activities, as a result of heavy caregiving responsibilities (14). A 2006 study by Bedini and Gladwell reviewed the obstacles to recreational travel in family caregivers, and argued that some of these barriers are intrapersonal barriers, and one of these intrapersonal barriers is the heavy care duties and responsibilities in the family that prevents them from engaging in leisure activities (18), which its results are consistent with the results of the present study. Joining supportive groups, having the opportunity to share experiences and responsibilities with someone else, increasing the number of daily care centers in the country, having the patient spend time in these centers and taking a break from caregiving tasks can be approaches to helpful strategies.

One of the other barriers to spending time on leisure by the family caregivers was their constant concern about the course of the illness, the treatment process, the side effects of drugs, the future of the illness and the future of the patient. Having a family member with mental illness imposes concern and pressure on caregivers and other family members (32). A 2010 study by Johansson et al. showed that caregivers having a mentally ill child say that their minds are constantly engaged with their ill child. Even when they are at work, they have disruption and permanent concern about their child's health and issues (30). A 2006 study by Rose et al. showed that caregivers of psychiatric patients have many concerns about their illness. One of these concerns is how to adapt to grief or mourning, the continuation of drug treatment by the patient, and how to communicate with health care providers. One of the most important concerns of family caregivers was concern over the patient's future, disappointment about the future, also disappointment about the treatment of patient in the future, together with the patient's control on the future and handling disruptive behavior. Also, the concern for continued increase of patient responsibilities in the future was also very concerning for caregivers, "Who would take care of their patient if they died one day and they were no more?" (4). In the present study, the participants said that these concerns and worries prevented them from thinking and paying attention to other things including leisure, and in some cases, made them completely ignore their own affairs and in particular their recreational activities. The findings from the study show that feelings of sympathy and rejection and social stigma were among factors that prevented family caregivers from engaging in leisure activities. Participants have stated that being pitied by people around them is one of the obstacles to their leisure activities. Sometimes, friends and relatives have rejected the patient due to certain behaviors from the patient; this prevents the family caregiver from communicating with friends and relatives and engaging in recreational activities. Some studies have shown that people in the community have negative stereotypical thoughts and are biased towards psychiatric patients. For example, they believe that these patients are dangerous or show negative or unpleasant emotional reactions (36). These negative thoughts can affect the lives of this group of people and their caregivers, and this point of view makes individuals in the community discriminate, or pity them, which also leads to them becoming neglected and rejected (29). 
Social stigma was one of the other obstacles that the participants pointed out. The mental patient stigma, societal tendency is based on viewing mentally ill persons as weak or dangerous and that they must be excluded (4). Not only the patient himself, but his family are also faced with this stigma, which causes social isolation and exclusion $(29,31)$. A study in the United States showed that $56 \%$ of family members of mentally ill patients experience social stigma. Social stigma has cognitive and affective effects on caregivers and they may react behaviorally. Among these behavioral responses, feeling of distress and helplessness in caregivers, hiding their status from others, secrecy about the disease, not following or delaying the treatment of the diseased family member, abandoning the patient, and withdrawing social relations can be mentioned (37). A 2006 study by Bedini and Gladwell stated that one of the barriers to leisure in family caregivers was social stigma, which was an interpersonal barrier, saying that social stigma, negative attitudes of others and lack of social protection are some of the major barriers in the way of caregiver's engagement in leisure activities (18). The results of this study were in line with our findings in the present study. Psychoeducation can be effective in reducing stigmatization. Family caregivers need some education regarding concept of mental illness and disease process, its causes, erroneous ideas about mental illness, stigmatization and skills for coping with stigmatization, hospital and community resources and a supportive social network.

\section{Limitations}

Since these findings are from a qualitative research design, they lack generalizability. The other prominent limitation was that this study was conducted in Tehran. Hence, the sample selected cannot be taken as a representative of the general Iranian population of family caregivers. Thus, further studies on Iranian family caregivers in different cultures and sub-cultures in urban and rural areas are recommended. This research was based on the experiences of family caregivers of people with chronic psychiatric disorders in exploring the barriers to leisure and provided useful information in this regard, but the study of this phenomenon from the perspective of other family members who live with a patient and the viewpoints of therapists in the field of mental health is also necessary. Therefore, further research is suggested in this regard.

\section{Conclusions}

The results of this research as the first qualitative research done in this field in Iran, can explore the obstacles of leisure from the viewpoint of family caregivers of people with chronic psychiatric disorders. According to this study, barriers to leisure in this group of family caregivers included patient, caregiver and community related factors that erect many barriers and challenges for family caregivers in dealing with leisure. It seems that paying attention to these barriers and to the educational needs of family caregivers, timely treatment of patients and their follow-up and the existence of day-care centers and counseling centers for patients and their families and caregivers can help to some extent, overcome these obstacles. The results of the current research can provide a broad view to mental health therapists in Iran to understand the needs and barriers of leisure in this group of caregivers, and remove these obstacles and family caregivers' concerns in dealing with leisure.

\section{Acknowledgments:}

We gratefully acknowledge all the participants in this research who agreed to participate in this study and honestly provided their valuable experiences. Also, our thanks go to the University of Social Welfare and Rehabilitation Sciences for their official support and those who cooperated with the research project. This study was adapted from the first author's $\mathrm{PhD}$ thesis and was approved by the ethics committee of the University of Social Welfare and Rehabilitation Sciences (ethical code: IR.USWR.REC.1394.38). This research received no specific grant support from any funding agency in the public, commercial, or not-for-profit sectors.

\section{Conflict of Interest:}

There is no conflict of interest to be declared.

\section{Authors' contributions:}

All authors contributed to this project and article equally. All authors read and approved the final manuscript.

\section{References:}

1) World Health Organization. Millions with mental disorders deprived of treatment and care. Available from: http://www.who.int/mediacentre/news/release/2008/pr37/en. 
2) Early M. Mental health concepts and techniques for hte occupational therapy assistant. 4th ed. USA: Lippincott Williams \& Wilkins; 2009.

3) Cara E, MacRae A. Psychosocial occupational therapy: A clinical practice. 2nd ed. Canada: Thomson; 2013.

4) Rose LE, Mallinson RK, Gerson LD. Mastery, burden, and areas of concern among family caregivers of mentally ill persons. Arch Psychiatry Nurs. 2006; 20(1): 41-51. doi: 10.1016/j.apnu.2005.08.009. PMID: 16442473.

5) Bertrand RM, Saczynski JS, Mezzacappa C, Hulse M, Ensrud K, Fredman L. Caregiving and Cognitive Function in Older Women Evidence for the Healthy Caregiver Hypothesis. J Aging Health. 2012; 24(1): 48-66. doi: 10.1177/0898264311421367. PMID: 21934121, PMCID: PMC4023537.

6) Bastawrous M. Caregiver burden-A critical discussion. Int J Nurs Stud. 2013; 50(3): 431-41. doi: 10.1016/j.ijnurstu.2012.10.005. PMID: 23131724.

7) Fekete C. Caregiver burden. International encyclopedia of the social \& behavioral science. 2015: 135-8.

8) Baronet AM. Factors associated with caregiver burden in mental illness: a critical review of the research literature. Clin Psychol Rev. 1999; 19(7): 819-41. doi: 10.1016/S0272-7358(98)00076-2. PMID: 10520437.

9) Marks NF, Lambert JD, Jun H, Song J. Psychosocial moderators of the effects of transitioning into filial caregiving on mental and physical health. Res Aging. 2008; 30(3): 358-89. doi: 10.1177/0164027507312998. PMID: 18725964, PMCID: PMC2519005.

10) De Silva D, De Silva S. A preliminary study of the impact of long term psychotic disorder on patients' families. Ceylon Med J. 2001; 46(4): 121-3. doi: 10.4038/cmj.v46i4.6429. PMID: 12164027.

11) Carbonneau H, Caron CD, Desrosiers J. Effects of an adapted leisure education program as a means of support for caregivers of people with dementia. Arch of gerontol Geriatr. 2011; 53(1): 31-9. doi: 10.1016/j.archger.2010.06.009. PMID: 20598758.

12) Occupational therapy practice framework: Domain and process (3rd Edition). Am J Occup Ther. 2014; 68(Supplement-1): S1- 48.

13) Bedini L. Family caregivers and leisure: an oxymoron? Parks \& Recreation. 2002; 37(1): 25-31.

14) Bedini LA, Guinan DM. "If I could just be selfish...": Caregivers' perceptions of their entitlement to leisure. Leisure Sciences. 1996; 18(3): 227-39. doi: 10.1080/01490409609513284.

15) Bedini LA, Phoenix TL. Perceptions of leisure by family caregivers: A profile. Ther Recreation J. 2004; 38(4): 366.

16) Gladwell NJ, Bedini LA. In search of lost leisure: the impact of caregiving on leisure travel. Tourism Management. 2004; 25(6): 685-93. doi: 10.1016/j.tourman.2003.09.003.

17) National Family Caregiver Association. Family care giving demands recognition "Care giving across the life cycle". Kensington, MD; 1998.

18) Bedini L, Gladwell N. Barriers to leisure travel of family caregivers: A preliminary examination. Topics in Geriatric Rehabilitation. 2006; 22(4): 322-33. doi: 10.1097/00013614-200610000-00007.

19) Stevens A, Coon D, Wisniewski S, Vance D, Arguelles S, Belle S, et al. Measurement of leisure time satisfaction in family caregivers. Aging Ment Health. 2004; 8(5): 450-9. doi: 10.1080/13607860410001709737. PMID: 15511743.

20) Losada A, Pérez-Peñaranda A, Rodriguez-Sanchez E, Gomez-Marcos MA, Ballesteros-Rios C, RamosCarrera IR, et al. Leisure and distress in caregivers for elderly patients. Arch gerontol Geriatr. 2010; 50(3): 347-50. doi: 10.1016/j.archger.2009.06.001. PMID: 19573933.

21) Mehrdad N, Oskouie F, Seyed Fatemi N. Qualitative content analysis. 1th ed. Boshra Publication; 2013.

22) Mohammadpur A. Qualitative research method counter method 1, The logic and design in qualitative methodology. 1th ed. Jameeshenasan Publication; 2011.

23) Graneheim UH, Lundman B. Qualitative content analysis in nursing research: concepts, procedures and measures to achieve trustworthiness. Nurse Education Today. 2004; 24(2): 105-12. doi: 10.1016/j.nedt.2003.10.001. PMID: 14769454.

24) Neuendorf KA. The Content Analysis Guidebook. Thousand Oaks, California: Sage Publications; 2002.

25) Guba EG. ERIC/ECTJ Annual Review Paper: Criteria for Assessing the Trustworthiness of Naturalistic Inquiries. Educational Communication and Technology. 1981; 29(2): 75-91.

26) Bedini LA, Phoenix TL. Addressing leisure barriers for caregivers of older adults: A model leisure wellness program. Ther Recreation J. 1999; 33(3): 222.

27) Jagannathan A, Thirthalli J, Hamza A, Nagendra H, Gangadhar B. Predictors of family caregiver burden in schizophrenia: Study from an in-patient tertiary care hospital in India. Asian J Psychiatr. 2014; 8: 94-8. doi: 10.1016/j.ajp.2013.12.018. PMID: 24655636. 
28) Zhou Y, Ning Y, Rosenheck R, Sun B, Zhang J, Ou Y, et al. Effect of living with patients on caregiver burden of individual with schizophrenia in China. Psychiatry Res. 2016; 245: 230-7. doi: 10.1016/j.psychres.2016.08.046. PMID: 27562225.

29) Gary FA. Stigma: Barrier to mental health care among ethnic minorities. Issues Ment health Nurs. 2005; 26(10): 979-99. doi: 10.1080/01612840500280638. PMID: 16283995.

30) Johansson A, Anderzen-Carlsson A, Åhlin A, Andershed B. Mothers' everyday experiences of having an adult child who suffers from long-term mental illness. Issues Ment Health Nurs. 2010; 31(11): 692-9. doi: 10.3109/01612840.2010.515768. PMID: 20936890.

31) Chou KR. Caregiver burden: a concept analysis. J Pediatr Nurs. 2000; 15(6): 398-407. doi: 10.1053/jpdn.2000.16709. PMID: 11151480.

32) Sharif F, Ghofranipoor F, Zoladl M. Phenomeological study of the experience of families with mental patients. Iranian Psychiatry and Clinical Psychology. 2006; 12: 1-2.

33) Yıkılkan H, Aypak C, Görpelioğlu S. Depression, anxiety and quality of life in caregivers of long-term home care patients. Arch Psychiatr Nurs. 2014; 28(3): 193-6. doi: 10.1016/j.apnu.2014.01.001. PMID: 24856272.

34) Family Caregiver Alliance. Fact sheet: Selected caregiver statistics. San Francisco, CA: Family Caregiver Alliance. 2001; 19: 2011.

35) Rosenthal CJ, Sulman J, Marshall VW. Depressive symptoms in family caregivers of long-stay patients. Gerontologist. 1993; 33(2): 249-57. PMID: 8468018.

36) Corrigan PW, Watson AC, Warpinski AC, Gracia G. Stigmatizing attitudes about mental illness and allocation of resources to mental health services. Community Ment Health J. 2004; 40(4): 297-307. PMID: 15453083.

37) Singh A, Mattoo SK, Grover S. Stigma and its correlates among caregivers of schizophrenia: a study from North India. Psychiatry Res. 2016; 241: 302-8. doi: 10.1016/j.psychres.2016.04.108. PMID: 27232551. 